\title{
RACISMO INSTITUCIONAL E ORDENS DE DESPEJOS NOS QUILOMBOS MATA CAVALOE JACARÉ DOS PRETOS, MATO GROSSO
}

Thaisa Maira Rodrigues Held (D)

Universidade Federal da Grande Dourados | Dourados - MS - Brasil 
O artigo trata da atuação do judiciário nas ordens de despejo de famílias quilombolas nos territórios de Mata Cavalo e Jacaré dos Pretos, em Nossa Senhora do Livramento, estado de Mato Grosso, à luz do racismo institucional. Tem por objetivo demonstrar que o perfil do judiciário brasileiro tem relação com sua atuação em situações que envolvem a população negra, abordando casos de crimes de racismo, mas sobretudo em ações de reintegração de posse envolvendo conflitos de interesses de não quilombolas. Foi utilizado o método dedutivo, uma vez que parte da leitura de conceitos e de dados gerais em relação ao racismo institucional para uma análise dos casos particulares de dois territórios quilombolas. Para isso, foi utilizada a análise de documentos e de conteúdo das decisões judiciais, tendo como parâmetro as diretrizes legais. Conclui-se que a atuação paradoxal do Estado, que, apesar de reconhecer o direito ao território quilombola, o nega, seja pela não implementação das políticas de regularização fundiária, seja pela atuação violenta do judiciário nos despejos forçados, caracterizando-se nítida materialização do racismo institucional.

Palavras-chave: território quilombola; judiciário; despejos; racismo institucional.

\section{INSTITUCIONAL RACISM AND EVICTION ORDERS IN THE QUILOMBOS MATA CAVALO AND JACARÉ DOS PRETOS, MATO GROSSO}

\section{ABSTRACT}

The paper deals with the performance of the judiciary in the eviction orders of quilombola families in the territories of Mata Cavalo and Jacaré dos Pretos, in Nossa Senhora do Livramento, state of Mato Grosso, in the light of institutional racism. Its aims to demonstrate that the profile of the Brazilian judiciary is related to its performance in situations involving the black population, addressing cases of crimes of racism, but above all in repossession actions involving conflicts of interest of non-quilombolas. The deductive method was used, since it starts from reading of general concepts and data in relation to institutional racism for an analysis of the particular cases of two quilombola territories. For this, the analysis of documents and the content of court decisions was used, taking legal guidelines as a parameter. It is concluded that the paradoxical performance of the State, which despite recognizing the right to quilombola territory, denies it, either due to the non-implementation of land tenure regularization policies, or due to the violent performance of the judiciary in forced evictions, characterized by a clear materialization of institutional racism.

Keywords: quilombola territory; judiciary; evictions; institutional racism.

\section{RACISMO INSTITUCIONAL Y ÓRDENES DE DESALOJO EN LOS QUILOMBOS MATA CAVALO Y JACARÉ DOS PRETOS, MATO GROSSO}

El artículo analiza las actuaciones del poder judicial a la luz del racismo institucional en las órdenes de desalojo de las familias quilombolas en los territorios de Mata Cavalo y Jacaré dos Pretos, en Nossa Senhora do Livramento, estado de Mato Grosso. Su objetivo es demostrar que el perfil del poder judicial brasileño está relacionado con sus acciones en situaciones que involucran a la población negra, abordando casos de crímenes de racismo, pero sobre todo en acciones judiciales de reintegración de posesión que involucran conflictos de intereses de personas que no son quilombolas. Se utilizó el método deductivo, ya que parte de conceptos y datos generales en relación con el racismo institucional para un análisis de los casos particulares de dos territorios quilombolas. Para ello, se llevó a cabo el análisis de documentos y de contenido de las decisiones judiciales, utilizando pautas legales como parámetro. Se concluye que la actuación paradójica del Estado se caracteriza por una clara materialización del racismo institucional, ya que a pesar de reconocer el derecho al territorio quilombola lo niega, ya sea por la no implementación de políticas de regularización de la tenencia de la tierra o por la acción violenta del poder judicial en los desalojos forzosos.

Palabras clave: territorio quilombola, 


\section{INTRODUÇÃO}

O direito à titulação dos territórios quilombolas é previsto no artigo 68, do Ato das Disposições Constitucionais Transitórias (ADCT), da Constituição de 1988. O dispositivo transitório cuja eficácia somente será exaurida quando todos os territórios forem totalmente titulados - torna o Estado responsável por implementar políticas públicas de regularização fundiária, não tratando mais do tema como exclusivamente cultural (Arruti 2009:79). Em mais de 31 anos de Constituição, sobretudo após a serem instituídos os decretos que regulamentam a implementação desses territórios, somente 269 das mais de 3.000 comunidades possuem pelo menos a titulação parcial de suas terras (CPISP 2020). Vale reforçar que a titulação parcial não contempla a norma constitucional, tampouco o direito à autodeterminação dos povos, previsto na Convenção n. 169, da Organização Internacional do Trabalho (OIT), tratado do qual o Brasil é signatário.

Apesar de todo o esforço dos pesquisadores da Antropologia em ressemantizar o conceito ultrapassado de quilombo (ABA 1994), forjado desde o Conselho Ultramarino, em 1740, este ainda é utilizado no meio jurídico e ainda figura no imaginário social, em uma noção folclórica que invisibiliza a realidade de quilombolas rurais e urbanos e torna cada vez mais distante a implementação do direito à regularização de suas terras. O território, em seu aspecto étnico, é imprescindível à manutenção dos modos de ser, fazer e viver, e não se enquadra na noção civilista de propriedade privada, devendo ser interpretado em conjunto com os artigos 215 e 216 da Constituição, que tratam do aspecto imaterial dos territórios.

Os obstáculos à materialização do direito dos quilombolas refletem um país que não buscou reparar a dívida histórica da escravidão. Enquanto não se titulam os territórios quilombolas, suas comunidades ficam expostas a todo o tipo de violência: das ameaças e agressões físicas e psicológicas às tentativas e assassinatos de lideranças; da invasão por não quilombolas; de especulações imobiliárias às ordens de despejo em ações de reintegração de posse; do racismo individual em agressões de particulares ao racismo institucional, seja por parte de agentes do executivo ou do judiciário. Os quilombolas não têm acesso a direitos básicos, tampouco às políticas diferenciadas, como a garantia de seu território, inerente à manutenção sociocultural.

A pesquisa não trata da análise dos autos dos processos, mas das discussões jurídicas a respeito dos direitos territoriais quilombolas, tendo como norte as decisões publicadas mais recentes sobre os despejos em Mata Cavalo e Jacaré dos Pretos, enquanto suas comunidades buscam a 
implementação do artigo 68 do ADCT. O objetivo aqui é compreender como o Estado, que tem o dever de garantir a titulação dos quilombos, tem agido, sobretudo nas discussões judiciais.

Nesse sentido, o presente artigo está dividido em duas partes. A primeira busca compreender o processo de marginalização da população negra após a abolição formal da escravidão no Brasil, em aspectos econômicos e sociais, incluindo o acesso à terra dos quilombolas, discutindo-se também como o racismo se materializa nas instituições, sobretudo no sistema de justiça, quando se analisa o perfil dos componentes do judiciário brasileiro e as consequências em sua atuação nos casos envolvendo os negros como vítimas de racismos e também como reivindicantes de seu direito constitucional ao território. A segunda parte trata, em um primeiro momento, das diretrizes sobre atuação do judiciário em ações de reintegração de posse que envolvem comunidades quilombolas à luz dos direitos fundamentais, sendo analisada, em seguida, a atuação nos casos dos despejos nos territórios quilombolas de Mata Cavalo e Jacaré dos Pretos, município de Nossa Senhora do Livramento, estado de Mato Grosso, à luz do racismo institucional, buscando-se lançar luz sobre o perfil de quem tem o dever de promover a justiça social.

\section{O RACISMO INSTITUCIONAL E 0 PERFIL DO JUDICIÁRIO BRASILEIRO}

Assinada em 13 de março de 1888, a lei que pôs fim - ao menos no sentido formal - aos mais de trezentos anos de escravidão no Brasil não significou plena liberdade aos negros: despossuídos de educação formal e de bens, quando conseguiam, ocupavam postos de trabalho em condições muito aproximadas à escravização. Sem teto, formaram suas comunidades, segregadas do centro e sem qualquer estrutura digna. Situações como criminalidade da juventude e prostituição de mulheres negras permeavam a triste realidade brasileira. Para Nascimento (2019:87-89), "se a escravidão significou crime hediondo contra cerca de trezentos milhões de africanos, a maneira como os africanos foram 'emancipados' em nosso país não ficou atrás como prática de genocídio cruel”. Sobre a marginalização dos negros no pósabolicionismo:

[...] colocaram-no como igual perante a lei, como se no seu cotidiano da sociedade competitiva (capitalismo dependente) que se criou esse princípio ou norma não passasse de um mito protetor para esconder desigualdades sociais, econômicas, étnicas. O Negro foi obrigado a disputar a sua sobrevivência social, cultural e mesmo biológica em uma sociedade secularmente racista, na qual as técnicas de seleção profissional, cultural, política e étnica são feitas para que ele permaneça imobilizado nas camadas mais oprimidas, exploradas e subalternizadas. [...] O racismo brasileiro, como vemos, na sua 
estratégia e nas suas táticas age sem demonstrar a sua rigidez, não aparece à luz, é ambíguo, meloso, pegajoso, mas altamente eficiente nos seus objetivos (Moura 1994:160).

O país, cujas raízes mais profundas se sustentam na escravidão e na exploração de corpos e natureza, na herança capitalista europeia, com acumulação de terras e bens, às custas de esbulhos e misérias de povos indígenas, comunidades quilombolas e tradicionais, foi maquiado pelo mito da democracia racial. A cordialidade do homem branco e a pacífica convivência entre escravizados e escravizadores foram forjadas por Gilberto Freyre, em "Casa Grande e Senzala”, mas desconstruídas pela realidade social do país, que "[...] largou o negro ao seu próprio destino, deitando sobre seus ombros a responsabilidade de se reeducar e de se transformar para corresponder aos novos padrões e ideais de ser humano, criados pelo advento do trabalho livre, do regime republicano e do capitalismo" (Fernandes 2008:35-36).

Nesse aspecto, é importante considerar o destino dos quilombolas a partir de 1888, sobretudo em relação aos seus territórios que, para Munanga (2001:30), “[...] são espécies de campos de iniciação à resistência, campos esses abertos a todos os oprimidos da sociedade: negros, índios e brancos, prefigurando um modelo de democracia plurinacional que o Brasil ainda está a buscar”. A concentração de terras e o modelo capitalista de monocultura em larga escala foram reforçados no contexto pós-abolição, cuja expropriação dos quilombolas de seus territórios prolonga o que Leite (2018:966) denomina de "processo de dominação continuada”. Silvio Almeida (2018:32) explica que o racismo institucional está inserido em um sistema mais abrangente, o racismo estrutural, que permite que indivíduos atuem de forma isolada ou em grupo em setores como a política e o direito, mas também com o apoio das instituições, que “[...] são hegemonizadas por determinados grupos raciais que utilizam mecanismos institucionais para impor seus interesses políticos e econômicos”.

$\mathrm{O}$ racismo estrutural se materializa nas instituições em diversas situações, seja na imposição de barreiras que dificultam o acesso a direitos fundamentais, como saúde, moradia, educação, alimentação e justiça, seja no perfil preponderante dos ocupantes de cargos de instituições de justiça e no tratamento dado em casos que envolvem a população negra. Para S. Almeida (2018:29-32), a materialização do racismo se dá pelas práticas discriminatórias de forma sistêmica, isoladas ou conjuntas, nos diversos cenários políticos, econômicos e sociais, com a identificação de condições de subalternidade e de privilégios entre grupos sociais, que geram conflitos de interesses, por vezes mantidos sob 
controle pelos meios institucionais, como o Poder Judiciário, composto em sua maioria por pessoas brancas, do sexo masculino, em condições econômicas favoráveis, reunindo privilégios que os negros sequer alcançaram.

O Brasil se declarou um país racista em 2005, com a adoção do Programa de Combate ao Racismo Institucional (PCRI), reconhecendo o fracasso das instituições em prover serviços adequados, seja pela adoção de práticas discriminatórias, seja por normas que impõem obstáculos cada vez mais altos às pessoas negras: "Em qualquer caso, o racismo institucional sempre coloca pessoas de grupos raciais ou étnicos discriminados em situação de desvantagem no acesso a benefícios gerados pelo Estado e por demais instituições e organizações” (PCRI 2006:22).

Ao longo dos anos, vários levantamentos sociodemográficos comprovaram que o Brasil é um país racista, apesar de muitos indivíduos não se afirmarem como tal. O intuito das pesquisas é demonstrar, de acordo com uma análise qualitativa dos dados, que o racismo está impregnado na estrutura social, se enraizando nas instituições e normatizando práticas segregacionistas. Para exemplificar, segundo a Pesquisa Nacional por Amostra de Domicílios Contínua (PNAD Contínua), do Instituto Brasileiro de Geografia e Estatística (IBGE), em 2018,
$56,10 \%$ dos brasileiros se declararam pretos ou pardos. Embora numericamente correspondam à maioria da população, os negros são minoria em postos de trabalho com maior remuneração (IBGE 2018). O estudo Desigualdades Sociais por Cor ou Raça no Brasil também identificou que $64,2 \%$ dos negros estavam desempregados ou em subemprego (IBGE 2018). Em relação aos quilombolas, Arruti \& Dowbor (2015) apontam as desigualdades sociais em diversos aspectos, entre eles o valor do rendimento médio nominal mensal nos territórios quilombolas, bem menor em comparação aos negros não quilombolas, por exemplo. A disparidade é ainda maior em comparação com os brancos. Em relação à educação, as taxas de alfabetização, sobretudo nos quilombos rurais, estão abaixo do nível nacional.

Estes dados e informações refletem a estrutura social marcada pela falta de acesso às políticas públicas por parte dos quilombolas, mantendo-os à margem do desenvolvimento econômico e social e vulneráveis às violências praticadas por indivíduos e pelo próprio Estado. O relatório "Racismo e violência contra quilombos no Brasil”, divulgado pela Coordenação Nacional de Articulação das Comunidades Negras Rurais Quilombolas (CONAQ) e pela organização Terra de Direitos, disponibiliza dados coletados entre os anos de 2008 e 2017 relativos ao racismo institucional contra 
quilombolas. De todos os registros de violência no ano de 2017, destaca-se que o maior índice de ocorrência é o relativo ao racismo institucional (32\%); em segundo plano, o latifúndio, que motivou $24,8 \%$; seguido dos megaprojetos socioambientais, responsáveis por 20,8\% de violência; e, finalmente, pela especulação imobiliária, com $11,8 \%$. O relatório aponta 2017 como o ano mais violento, e como agentes violadores de direitos indivíduos interessados nas áreas, grupos empresariais e as próprias instituições, atuando direta ou indiretamente nos conflitos:

O racismo institucional, o latifúndio e os megaprojetos-socioambientais foram os contextos que se associaram, em maior número, às ocorrências de violações de direitos em territórios quilombolas no ano de 2017. O dado chama atenção para provável co-constituição entre modelo de desenvolvimento socioeconômico atrelado a grandes obras e megaempreendimentos e o racismo das instituições públicas e também privadas. As políticas e as estratégias de desenvolvimento não têm sido neutras no que diz respeito à opressão de raça. Da mesma forma, a existência de latifúndios, associada à prática sistemática de violações de direitos dos quilombolas, denota certa permissividade político-jurídica estrutural com o regime classista de propriedade de terras no país, quem tem impedido o povo negro de defender seu território e seus modos de vida constitucionalmente assegurados (CONAQ \& Terra de Direitos 2018:84).

No Poder Judiciário, segundo levantamento feito pelo Conselho Nacional de Justiça (CNJ) em
2018, o perfil da magistratura brasileira é traçado pela supremacia masculina branca: $80,3 \%$ dos juízes são brancos, $18 \%$ são negros e $1,6 \%$ de origem asiática. A pesquisa apurou, ainda, que $0,1 \%$ dos magistrados se declarara indígena (CNJ 2018). O órgão providenciou uma audiência pública para debater modificações na Resolução 75/2009, que trata dos concursos públicos para ingresso na magistratura. Na ocasião, a Articulação Justiça e Direitos Humanos (JusDh), representada pela advogada quilombola Vercilene Francisco Dias, do território Kalunga, município de Cavalcante, estado de Goiás, chamou atenção para os dados publicados pelo $\mathrm{CNJ}$ sobre o perfil do judiciário brasileiro e contribuiu com propostas para modificação de critérios relacionados à meritocracia, a fim de que o judiciário possa ter maior representatividade étnica e social, com aprofundamento da qualidade técnica, indispensável em um Estado Democrático de Direito (JusDh 2019).

O levantamento feito pelo Grupo de Estudos Multidisciplinares da Ação Afirmativa sobre a desigualdade racial entre os anos 1988 a 2015 demonstra que, nos tribunais superiores, a disparidade entre brancos e negros é ainda maior: $1,3 \%$ se declaram pretos e 7,6\% pardos, sendo que apenas um negro integrou o Supremo Tribunal Federal (STF) desde sua criação, Joaquim Barbosa. No Superior Tribunal de Justiça (STJ), apenas o 
ministro Benedito Gonçalves; no Tribunal Superior do Trabalho (TST), apenas os ministros Carlos Alberto de Paula e Horácio Raymundo de Senna Pires (Venturini \& Feres Júnior 2020).

Esses dados nos permitem indagar quais seriam os reflexos deste perfil na atuação em demandas que envolvem o negro, vítima de racismo, além dos conflitos que envolvem territórios quilombolas. Nesse sentido, a atuação do judiciário em alguns casos referentes a crimes de racismo e de despejos em comunidades quilombolas nos oferece subsídios para uma análise crítica de como o Estado tem se posicionado nestas questões. Em âmbito internacional, o Brasil foi o primeiro país a ser demandado no Sistema Interamericano de Direitos Humanos por racismo institucional. O caso Simone André Diniz versus Brasil foi analisado pela Comissão Interamericana de Direitos Humanos (CIDH), que considerou o racismo institucional brasileiro não somente neste caso, mas em tantos outros. Segundo o relatório n. 66/06:

\footnotetext{
Essa prática tem como efeito a discriminação indireta na medida em que impede o reconhecimento do direito de um cidadão negro de não ser discriminado e o gozo e o exercício do direito desse mesmo cidadão de aceder à justiça para ver reparada a violação. Demais disso, tal prática causa um impacto negativo para a população afrodescendente de maneira geral. Foi isso precisamente que ocorreu com Simone André Diniz, quando buscou a tutela judicial para ver sanada a violação de que foi vítima (CIDH 2006:6).
}

Santos (2015:191), em estudo sobre a atuação do judiciário paulistano em casos de racismo entre os anos 2003 e 2011, observou que uma pequena parcela dos processos penais recebeu sentença condenatória, ao passo que a maioria das denúncias foi rejeitada por falta de provas ou provas inconsistentes, por decadência de prazo para apresentação de queixa-crime (cometidos anteriores a 2009), ou desclassificada como crime de racismo, sendo considerada injúria racial. Também foi constatado, por meio de entrevistas, que os delegados de polícia, apesar do tratamento respeitoso em um primeiro contato, ofereciam resistência em lavrar boletins de ocorrência.

O mais recente e repercutido caso de racismo foi o apreciado pelo STF, que tem por objetivo o cumprimento da Constituição Federal, na denúncia sobre o crime de racismo contra o atual presidente da República Jair Bolsonaro. No dia 3 de abril de 2017, em um evento no Clube Hebraica, do Rio de Janeiro, o então deputado federal, pré-candidato à presidência, declarou que, se dependesse dele, não haveria mais nenhuma terra quilombola titulada, referindo-se aos quilombolas como animais: "O afrodescendente mais leve lá pesava sete arrobas. Não fazem nada. Eu acho que nem para procriador ele serve mais. Mais de $\mathrm{R} \$ 1$ bilhão por ano é gasto com eles”. Em 6 de abril de 2017, a CONAQ e a organização Terra de 
Direitos protocolaram uma representação contra Bolsonaro na Procuradoria-Geral da República (PGR), para que o órgão de cúpula do Ministério Público Federal (MPF) oferecesse denúncia crime contra o parlamentar. Nesse sentido, apresentou a notícia de fato por crime de racismo, previsto no artigo 20, da Lei n. 7.716/89: "praticar, induzir ou incitar discriminação ou preconceito de raça, cor, etnia, religião ou procedência nacional” (Brasil 1989). O documento, que também denunciou uma série de declarações contra refugiados, homossexuais e indígenas, chamou atenção para o fato de que tanto a nossa legislação interna quanto os tratados internacionais em que o Brasil é signatário rechaçam veementemente qualquer tipo de discriminação, e sobre a incitação odiosa e racista contra quilombolas reforçou:

Esta manifestação, inaceitável, alinha-se ao regime da escravidão, em que negros eram tratados como mera mercadoria, e à ideia de desigualdade entre seres humanos, o que é absolutamente refutado pela Constituição brasileira e por todos os Tratados e Convenções Internacionais de que o Brasil é signatário, que afirmam a igualdade entre seres humanos como direito humano universal e protegido (MPF 2018:5).

O crime de racismo é previsto na Constituição Federal brasileira e não se sujeita a fiança, conforme inciso XLII, do artigo $5^{\circ}$ : "a prática do racismo constitui crime inafiançável e imprescritível, sujeito à pena de reclusão, nos termos da lei” (Brasil 1988).

Entretanto, a Primeira Turma do STF considerou que, embora moralmente reprovável, a conduta do parlamentar é acobertada pela liberdade de expressão relacionada à imunidade parlamentar, e por maioria a rejeitou; o caso foi arquivado, em razão da imunidade parlamentar de Bolsonaro. Em seu voto-vista, o Ministro Alexandre de Moraes, que desempatou a votação, justificou: "[...] apesar da grosseria, do erro, da vulgaridade, do desconhecimento das expressões, não me parece que a conduta do denunciado tenha extrapolado os limites de sua liberdade de expressão qualificada, que é abrangida pela imunidade material. Não teria extrapolado, a meu ver, para um discurso de ódio, xenofobia ou incitação ao racismo" (STF 2018:17).

Diante do descaso do STF, a CONAQ publicou nota de repúdio ao arquivamento do caso, atuação que, segundo o coletivo, não surpreende: “[...] Afinal, temos um Poder Judiciário composto, majoritariamente, por homens brancos, uma composição sem qualquer correspondência com a diversidade étnico-racial da sociedade brasileira e que dificulta muito a aplicação de penalidades raciais" (CONAQ 2019a).

A atuação do STF na Ação Direta de Inconstitucionalidade (ADI) 3.239, que questionava a constitucionalidade do decreto n. 4.887/2003, que regulamenta o artigo 68 do Ato das Disposições 
Constitucionais Transitórias (ADCT), promovida pelo atual partido Democratas (DEM) em 2004, fazia parte da articulação de representantes do agronegócio, por meio da ação promovida pelo partido. Por outro lado, foi formado um "campo de intervenção em defesa do decreto" (Araújo \& Silva 2019:200) na atuação como amicus curiae de coletivos de comunidades quilombolas, organizações não governamentais e advogados populares. Os quatorze anos de morosidade no julgamento da ação trouxeram insegurança jurídica para as mais de seis mil comunidades quilombolas, segundo levantamento da CONAQ. Apesar da derrota do DEM, com a improcedência da ação, em fevereiro de 2018, a tese do marco temporal de ocupação voltou a rondar o judiciário pelo voto do Ministro Dias Tóffoli, que entende ser necessária a comprovação de ocupação dos territórios na data da promulgação da Constituição Federal ou em caso de esbulho, de suspensão ou perda da posse em decorrência de atos ilícitos praticados por terceiros (STF 2018).

A atuação do judiciário, sobretudo em casos de maior repercussão, nos permite, assim, reafirmar o racismo institucional brasileiro e compreender como a sociedade age em conformidade com a sensação de impunidade, tanto no cometimento de crimes de racismo quanto na naturalização de condutas praticadas por agentes públicos ou privados contra a população negra de um modo geral e especialmente às comunidades quilombolas, que já são vulnerabilizadas pela falta de políticas públicas diferenciadas, como a regularização de seus territórios. A morosidade do Estado em titular os territórios quilombolas potencializa as vulnerabilidades socioambientais, situação que vem sendo levada à $\mathrm{CIDH}$ nos últimos anos por meio de denúncias feitas por coletivos e organizações não governamentais. Em 2017, foi apresentado o Informe de Carta 41, relatando como o executivo tem paralisado as titulações. No ano seguinte, houve oitiva no $169^{\circ}$ Período de Sessões da CIDH, em Bolder, nos EUA, e, em 2019, na audiência sobre a situação dos direitos humanos das comunidades quilombolas no Brasil, em Sucre, Bolívia, foi reforçada a morosidade na titulação e a intensificação da violência e dos assassinatos contra lideranças quilombolas.

\section{ATUAÇÃO DO JUDICIÁRIO NOS DESPEJOS EM MATA CAVALO E JACARÉ DOS PRETOS, EM MATO GROSSO}

Para se ter uma ideia de como o judiciário deve atuar em processos que envolvem conflitos pelos territórios quilombolas, é preciso considerar três aspectos: a) diferenciação da terra no sentido individual com o território étnico, ou seja, os modos de ser, fazer e viver das comunidades quilombolas; 
b) reconhecimento pelo Estado da comunidade quilombola, seja pela emissão da certificação da Fundação Cultural Palmares (FCP), seja pelo conteúdo do processo de regularização fundiária junto ao Instituto Nacional de Colonização e Reforma Agrária (INCRA), em se tratando da competência federal para regularização fundiária; c) caso exista discussão jurídica sobre propriedade da área, no todo ou em parte, existem diretrizes menos gravosas para as comunidades, se houver requerimento de reintegração de posse? Além disso, quando se trata de território quilombola, há vários aspectos a considerar. O primeiro reflete a falsa ideia da padronização das formas de ocupação inicial. Há locais ocupados pela fuga ao sistema escravagista; outros são doações dos senhores de terras aos santos ou aos próprios negros que lhes serviram, significando dizer que as mais variadas formas de ocupação dos ancestrais e dos que atualmente vivem nas terras devem ser consideradas. Além disso, a solidariedade e a reciprocidade nas atividades cotidianas, sobretudo na resistência à violência, são determinantes dos modos de vida (Beltrão \& Oliveira 2011; Bandeira 1990). A interpretação do uso que se faz da terra de distintas maneiras é necessária quando o judiciário tem como dever aplicar corretamente as leis para se fazer a justiça, sobretudo quando se discute posse e propriedade em terras quilombolas já reconhecidas pelo Estado. Déborah Duprat chama atenção para a prevalência do reconhecimento da propriedade privada em detrimento do direito constitucional ao território étnico:

\begin{abstract}
A prática judiciária, no entanto, tende a equiparar ambos os institutos, conferindo-lhes tratamento processual idêntico. Também aqui as ações possessórias são admitidas em abundância. Uma ação vocacionada à tutela de direito de cunho nitidamente civilista neutraliza a disciplina constitucional das "terras tradicionalmente ocupadas", porque a luta processual se desenvolve sob controle das normas constitutivas daquele campo e valendo-se apenas das armas nele autorizadas. Assim, elementos tais como posse velha, ocupação física, passam a ser acriticamente definitórios de direitos possessórios (Duprat 2018:120-121).
\end{abstract}

Desconsiderar a relação que as comunidades quilombolas têm com a terra é negar a história de resistência negra à escravidão e os direitos reconhecidos nos artigos 215, 216 e, sobretudo, no artigo 68 do ADCT da Constituição Federal. Estes dispositivos, embora estejam organizados separadamente pelos temas cultura e território, devem ser interpretados em conjunto para se compreender que o território quilombola transcende a noção de delimitação de uma área: é imprescindível à manutenção da identidade cultural, que passa de geração a geração.

Além disso, apesar de o direito à titulação dos quilombos estar em um dispositivo de cunho 
transitório, sua eficácia se mantém ao longo dos anos até que o dispositivo seja implementado de maneira satisfatória (Treccani 2006:84). Segundo levantamento feito pela organização Terra de Direitos (Schramm 2019), caso o ritmo atual de titulação se mantenha, serão necessários aproximadamente mil anos para que a eficácia do artigo 68 seja exaurida.

O Poder Judiciário tem papel importante na implementação do direito ao território quilombola, não pela atribuição, que é do INCRA, mas pela atuação como coadjuvante em processos judiciais que envolvem disputas pelo território, já reconhecido pelo órgão administrativo. Para Duprat (2018:120): "Definir os conflitos agrários atuais, em especial as ações de ocupação, como um problema de caráter civil, é negar o novo desenho que a Constituição conferiu ao tema, cujas bases estão assentadas numa relação pública, estabelecidas entre grupos e o Estado".

É preciso ainda considerar, à luz do Decreto n. 4.887/2003, como o Estado deve implementar o artigo 68 do ADCT no reconhecimento e na titulação dos territórios quilombolas, a começar pela definição. $\mathrm{O}$ artigo $2^{\circ}$, parágrafo primeiro, do decreto conceitua as comunidades quilombolas como grupos étnicos "[...] segundo critérios de autoatribuição, com trajetória histórica própria, dotados de relações territoriais específicas, com presunção de ancestralidade negra relacionada com a resistência à opressão histórica sofrida". E consideram os quilombos indispensáveis "[...] para a garantia de sua reprodução física, social, econômica e cultural" e que, para que se proceda a delimitação do território, “[...] serão levados em consideração critérios de territorialidade indicados pelos remanescentes das comunidades dos quilombos" (Brasil 2003).

Os critérios de autoatribuição dizem respeito ao direito à autodeterminação dos povos, previsto não somente na Convenção 169 da Organização Internacional do Trabalho (OIT), ratificado pelo Brasil. De acordo com o parágrafo quarto do artigo terceiro do Decreto 4.887/2003, o processo de regularização fundiária quilombola se inicia com a emissão de certidão à comunidade quilombola feita pela $\mathrm{FCP}$, documento que não garante a propriedade do território, mas indica que o órgão reconhece a existência e reivindicação do território pela comunidade.

De forma mais simplificada, o procedimento junto ao INCRA obedece às seguintes etapas: protocolo do pedido de abertura do processo administrativo com a certidão expedida pela FCP; realização do Relatório Técnico de Identificação e Delimitação (RTID) da área, com estudo antropológico; notificação de eventuais não quilombolas que estejam na área 
delimitada; período de resposta; publicação do decreto presidencial e eventuais processos de desapropriação; titulação da área em nome da associação quilombola para fins de registro em cartório. Essas etapas duram, em média, dez anos, morosidade que mantém os quilombolas à mercê de especulações imobiliárias, invasões e como vítimas de violências diversas, seja em episódios de racismo individual, como ameaças, assassinatos, destruição de casas e roçados, seja por parte do próprio Estado, em ações de reintegração de posse com o uso da violência em retirada de comunidades de seu território, como demonstrou o relatório da CONAQ e Terra de Direitos (2018).

Nesse aspecto, em se tratando de território ainda não titulado, mas com solicitação de reconhecimento na FCP ou por abertura de processo administrativo no INCRA, pode-se dizer que há um incipiente reconhecimento da comunidade pelo Estado e, caso haja disputa judicial pelo território, o juiz deve observar também a existência destas etapas administrativas não somente para subsidiar seu convencimento, além dos elementos do processo judicial, mas também para garantir a dignidade das comunidades quilombolas.

Para isso, é necessário observar com rigor as diretrizes previstas na Resolução n. 10, de
17 de outubro de 2018, do Conselho Nacional dos Direitos Humanos (CNDH), que tem como destinatários agentes e instituições do sistema de justiça, em casos que envolvam conflitos por territórios, como o caso dos quilombolas. Os parágrafos um e dois do artigo $1^{\circ}$ são claros ao dispor que os despejos forçados são violações de direitos humanos e que, até mesmo em casos de autorização judicial, os direitos humanos das comunidades devem prevalecer ao direito individual de propriedade. Vale destacar que o despejo é a última e não a única medida judicial, e que o uso da violência, seja ela qual for, é inadmissível:

Art. 14 Remoções e despejos devem ocorrer apenas em circunstâncias excepcionais, quando o deslocamento é a única medida capaz de garantir os direitos humanos. $\S 1^{\circ}$ Os deslocamentos não deverão resultar em pessoas ou populações sem teto, sem terra e sem território. $§ 2^{\circ}$ Não deverão ser realizadas remoções que afetem as atividades escolares de crianças e adolescentes, o acesso à educação e a assistência à pessoa atingida, que faz acompanhamento médico, para evitar a suspensão do tratamento. $\S 3^{\circ}$ Não deverão ser realizadas remoções antes da retirada das colheitas, devendose assegurar tempo razoável para o levantamento das benfeitorias.

Art. 19 O uso de violência física, psicológica, simbólica, constrangimento ilegal, ameaça, e qualquer apropriação dos pertences pessoais durante as remoções é ilegal e passível de responsabilização cível, criminal e administrativa, devendo ser observados o direito à intimidade, privacidade, não discriminação e dignidade humana (CNDH 2018, destaque nosso). 
A Resolução, apesar de recente no mundo jurídico, não traz nenhuma novidade a respeito da observância dos direitos fundamentais, já previstos em diversos artigos da Constituição Federal, como dignidade humana, igualdade formal e material, não discriminação, moradia, equilíbrio ambiental, regularização fundiária, cultura, educação e tantos outros que levaram à alcunha de Constituição Cidadã, somando-se a estes os direitos reconhecidos pelos tratados internacionais sobre direitos humanos em que o Brasil seja parte. Entretanto, diante de violações destes direitos, é necessário reforçá-los por meio de normativa específica, sobretudo em locais marcados pela violência no campo, como na região da Amazônia Legal, que concentrou nos primeiros cinco meses de $201741 \%$ dos registros de assassinatos (CPT 2017).

Estado que compõe a Amazônia Legal, Mato Grosso possui uma história marcada pela alta concentração de terra, com o apoio do governo para beneficiar posseiros e compradores ligados aos grupos que ocupavam cargos políticos (Moreno 1999). Uma das características do Estado é o agronegócio, que, por sua vez, desencadeia diversos conflitos agrários, cujos alvos são grupos sociais ligados ao campo, indígenas, assentados rurais, sem-terra e quilombolas. Segundo dados da CPT, Mato
Grosso ocupa a quarta posição no ranking de homicídios no campo e também possui números consideráveis de crimes de ameaças, danos materiais e pistolagem (CPT 2018). Segundo dados do INCRA (2019), apesar do registro de 73 processos de regularização fundiária, abertos entre os anos 2004 e 2016, até o momento, nenhum território quilombola foi titulado. A organização Comissão Pró-Índio de São Paulo (CPISP), que monitora, desde 2004, a implementação da regularização fundiária quilombola, identificou 75 quilombos (CPISP 2020), o que chama atenção para o fato de que o órgão federal não possui ou publica todos os dados, o que se percebe pela tabela referente ao andamento dos processos, disponibilizada em seu endereço eletrônico, que identifica apenas quatro comunidades, sendo que Mata Cavalo e Lagoinha de Baixo foram tituladas com publicação de decreto presidencial no Diário Oficial da União, e as comunidades Campina da Pedra e Laranjal, com publicação do relatório técnico (INCRA 2019).

Mesmo que em Mato Grosso tenham ocorrido conflitos envolvendo ações de despejo em outras comunidades quilombolas, optou-se pela análise, ainda que preliminar, de Mata Cavalo e Jacaré dos Pretos, localizados no município de Nossa Senhora do Livramento, 
a cerca de 90 quilômetros da capital do estado. Em ambos territórios, as tensões pela terra se dão no judiciário, em diversas ações possessórias e ações civis públicas, cujas discussões, em termos gerais, se dão em torno da comprovação da propriedade das áreas reivindicadas. Nesse sentido, a análise da atuação do judiciário é feita a partir das liminares de ordem de despejo em primeira instância e das decisões do tribunal que as anularam à luz do racismo institucional.

Mata Cavalo é o maior quilombo de Mato Grosso e em 2006, época da elaboração do RTID, foram catalogadas 418 famílias. Trata-se de um complexo sociobiodiverso, cujos modos de ser, fazer e viver são peculiares. A sobrevivência das famílias depende da pesca artesanal, da agricultura familiar, além da venda de doces e artesanatos. Organizadas em seis associações, as comunidades de Mata Cavalo foram as primeiras a reivindicarem o reconhecimento de seu território e, apesar de ter sido titulada pela FCP, que à época de vigência do Decreto 3.901/2001, tinha tal atribuição, o título não foi registrado em cartório, em razão de registros de outras propriedades na área (Held 2018:136-146).

O processo de regularização de Mata Cavalo encontra-se em fase de desapropriação dos imóveis registrados na área delimitada e desintrusão de não quilombolas, após publicação do decreto presidencial em 2009, etapa que corresponde à fase final do processo de regularização e é bastante conflituosa do ponto de vista dos interesses de terceiros, que empregam todo o tipo de violência para a retirada das famílias (Held 2017:76-77), situação registrada no Relatório da Missão ao Estado de Mato Grosso, elaborado pela Plataforma Brasileira de Direitos Humanos, Econômicos, Sociais, Culturais e Ambientais (DHESCA Brasil), em visita a Mata Cavalo, em 2004: “[...] enquanto a situação da área não é resolvida, há famílias inteiras morando em barracos de palha a poucos metros do asfalto, entre a rodovia e a cerca de fazendeiros que se apossaram da terra e impedem a entrada dos quilombolas" (DHESCA Brasil 2005:22).

A titulação do território não é garantia de que os conflitos cessem, mas garante às comunidades o registro da área, tal como determina o artigo 68 do ADCT, e impede ações violentas por parte do judiciário, requeridas por pretensos proprietários, como a que ocorreu em 9 de outubro de 2017, atendendo ao pedido dos herdeiros da fazenda Nova Esperança. Dezessete famílias foram surpreendidas por policiais federais armados e tiveram suas casas destruídas por tratores, com seus bens jogados às margens da rodovia que corta o território 


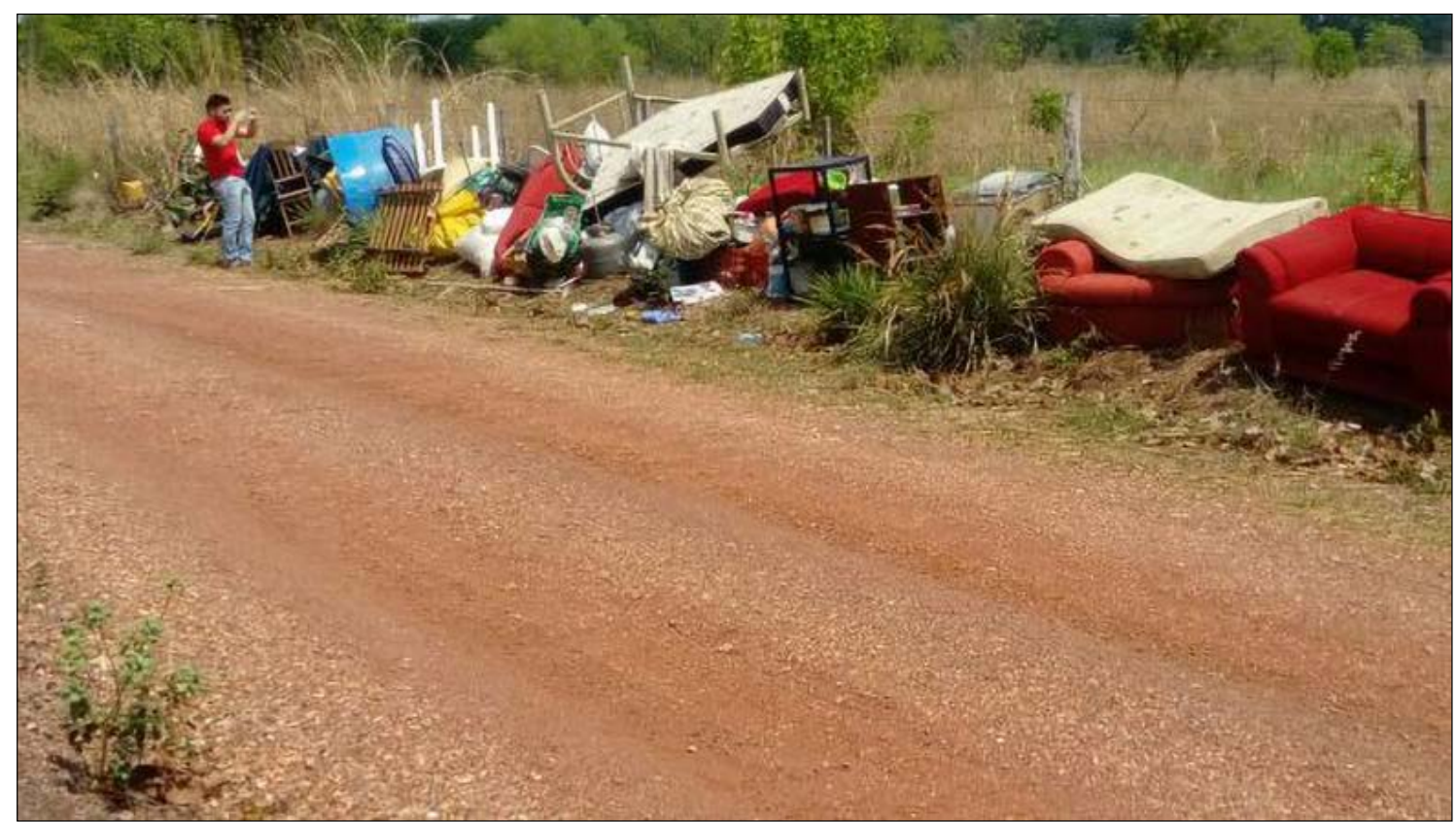

Figura 1 - Pertences jogados às margens da rodovia. Foto: Gonçalina de Almeida. Fonte: Gazeta Digital (2017).

(Figura 1). Sem ter para onde ir, as famílias que possuem raízes no território buscaram ajuda emergencial com amigos e familiares, foram chamadas de invasores pelo juiz da ação, Rafael Cazelli de Almeida Carvalho, que determinou multa em caso de descumprimento.

A decisão repete em escala local a cena de um ativismo judicial às avessas e reflete o racismo institucional brasileiro. Além de não possuir nenhum alicerce jurídico plausível, a deliberação é frágil quanto à prova das alegações do espólio do fazendeiro, como, aliás, o próprio juiz admitiu nos autos, ao afirmar que: "uma vez concluído o processo de desapropriação junto ao INCRA e realizada perícia judicial, caso necessário, o desfecho judicial muito provavelmente será diverso" (TRF1 2017). A FCP recorreu da decisão e, dois dias depois, a juíza Rogéria Castro Debelli, do Tribunal Regional Federal da Primeira Região (TRF1) (Agravo n. 1001316-37.2017.4.01.3600/MT), suspendeu os efeitos da decisão de Cazelli. Entretanto, as casas e os pertences já haviam sido destruídos sumariamente, e homens, mulheres, crianças e idosos não tinham ainda onde morar, e o Estado provavelmente não reparará os danos que esta violação de direitos humanos causou.

Outra atuação arbitrária do judiciário mato-grossense ocorreu no quilombo Jacaré dos Pretos, certificado pela FCP em 4 de agosto de 2005 e com processo de regularização aberto no INCRA no mesmo ano. Há mais 
de uma década, a área é disputada na justiça em ação de reintegração de posse, discussões sobre a competência para processar e julgar a matéria, além de ordens de despejos e anulações que tonaram os quilombolas alvo de diversas violências. Em 18 de setembro de 2019, a família do Sr. Ângelo Jesus de Campos foi retirada à força de seu território e teve a casa, os pertences e as plantações e árvores frutíferas destruídos por ordem da juíza Ester Belém Nunes Dias, em processo de reintegração de posse da fazenda Pirapora, promovido pela pecuarista Maria Terezinha Leite Nadaf, que tramita na vara cível de Várzea Grande, Mato Grosso (Figura 2). sendo ocupada tradicionalmente por gerações. A destruição é contada com muita tristeza por seu Ângelo Jesus de Campos, presidente da Associação Negra Rural Quilombo Jacaré dos Pretos e réu na ação de reintegração de posse:

O lugar onde morávamos virou
um deserto. Não tem mais nada, os
tratores derrubaram tudo; os pés
de caju, de laranja, de limão. A casa
que utilizávamos como escola para as
crianças e os adultos, tudo destruído.
Nossas roupas e nossos pertences até
agora não sabemos onde estão. Estou
na cidade, mas contrariado, minha
vida é dentro do território (apud
Barbieri 2019).

Em carta de repúdio, a CONAQ denuncia o racismo institucional no caso de Jacaré dos Pretos e reforça as violações de direitos humanos praticadas pelo judiciário, "[...] a qual impacta diretamente

A área está inserida no território quilombola,

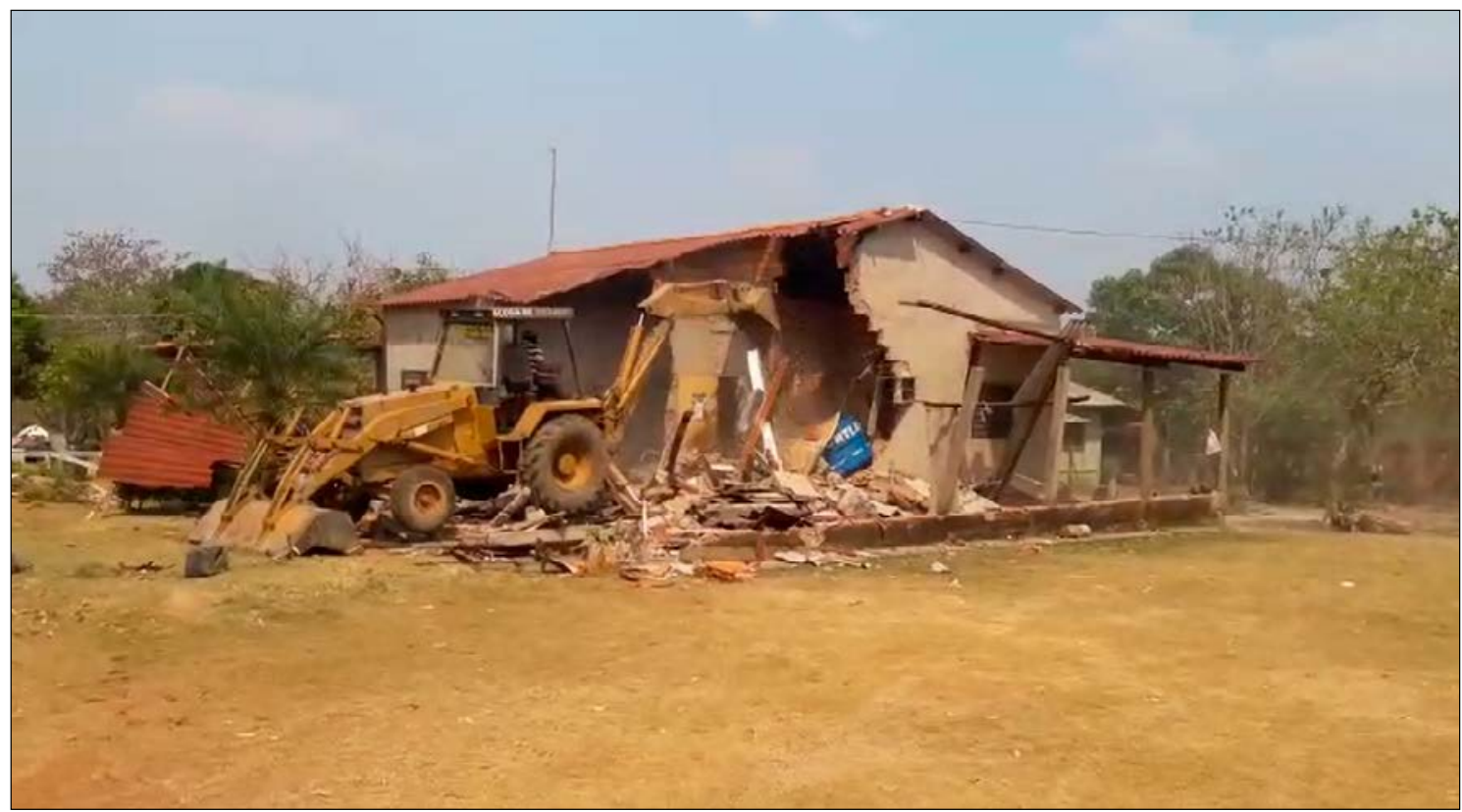

Figura 2 - Destruição da residência da família do Sr. Ângelo Campos. Fonte: Barbieri (2019). 
na história, cultura e memória da comunidade quilombola, impossibilitando a continuidade da luta dos seus ancestrais que ali habitavam" (CONAQ 2019b). O MPF e a FCP recorreram da decisão, que foi anulada pelo TRF1, em 19 de fevereiro de 2020, na Apelação Cível n. 000930519.2014.4.01.3600/MT. Segundo o acórdão:

\begin{abstract}
A Constituição Federal de 1988 reconheceu a finalidade pública das terras tradicionalmente ocupadas por quilombos, conferindo às comunidades a titularidade destas terras comprovadamente consagradas, como esforço de proteção da identidade cultural, étnica, e também de desenvolvimento social, econômico, cultural preservando-se o patrimônio histórico do país. [...] Mostra-se, portanto, ofensivo aos princípios do contraditório e da dialeticidade do processo interromper-se o fluxo processual com o julgamento antecipado da lide, sem que se oportunize às partes a produção de provas requeridas e que se apresentam necessárias à formação do juízo de convencimento acerca da referida questão fática (TRF1 2020).
\end{abstract}

Apesar da decisão do tribunal, a história dos quilombolas de Jacaré dos Pretos está longe de um desfecho justo, uma vez que a decisão suspende os efeitos jurídicos do despejo (que já violou o direito à moradia, ao território étnico e tantos outros atributos de dignidade humana) até a elaboração do RTID, pelo INCRA. Conforme artigo 17, do Decreto n. 4.887/2003, o relatório é elemento fundamental do processo administrativo de regularização fundiária, aberto em 2005, mas não há expectativa de quando será elaborado, tendo em vista a paralisação dos processos por falta de recursos do governo federal (INCRA 2019).

A atuação/omissão do Estado é bastante semelhante nos dois territórios quilombolas. No executivo, em que pese o processo de regularização fundiária esteja mais avançado em Mata Cavalo, é importante ressaltar que as associações requereram a titulação junto ao INCRA em 2004, ao passo que, em Jacaré dos Pretos, apesar de a abertura ter ocorrido em 2005, o processo está em fase de contratação de empresa para realização do RTID e por duas vezes sem êxito nos dois editais de pregão eletrônico. Há semelhança na atuação do judiciário em ambos os casos. A análise das decisões nos permite observar que os juízes de primeira instância, que possuem maior aproximação com as partes do processo, decidem de acordo com os interesses dos não quilombolas, não considerando anterior reconhecimento do território, seja pela FCP ou pelo INCRA, e seu efeito declaratório, pois a autoafirmação pressupõe a existência de um direito cujo teor dos documentos é apenas formalizar o que historicamente já existia. Ao julgar os pedidos de despejo sumário, feito por fazendeiros, os juízes não consideram também as peculiaridades do território quilombola, que diferem do sentido civilista de propriedade privada. Nesse sentido: 
É preciso refletir sobre a responsabilidade do Judiciário, especialmente no plano simbólico, de transmissão de uma mensagem de retorno à "velha ordem", onde o Estado é capturado por alguns poucos, que se sentem autorizados a encarnar em si o próprio direito. E, mais que tudo, está na hora de se exigir um Judiciário mais curioso e atento à novidade do que nostálgico de suas certezas (Duprat 2018:122).

As ordens de despejos, sumariamente cumpridas com o uso de violência contra mulheres e homens, crianças e idosos, refletem o racismo institucional, uma vez que arbitrárias, sem possibilidade de defesa por parte das comunidades, atendendo aos interesses dos ditos proprietários que, pelo poderio econômico, estão sempre em vantagem em relação aos quilombolas. Nesse sentido, o Estado, que tem o dever de efetivação do artigo 68 do ADCT, denega o direito humano ao território, potencializando a teia de violências que envolve as comunidades. A atuação célere do judiciário nos casos de despejo foi objeto de constatação no relatório "Conflitos no campo, Brasil 2018”, publicado pela Comissão Pastoral da Terra (CPT), segundo o qual o Estado está ligado, direta ou indiretamente, a ações violentas protagonizadas por grileiros contra comunidades tradicionais, incluindo quilombolas:

\footnotetext{
A facilidade com que o poder judiciário exara ordens de reintegração de posse, e a rapidez com que o faz, são expressão da dupla velocidade com que o estado se move: veloz, quando em defesa do andar de cima, e lento quando se trata
}

dos interesses dos grupos/classes sociais em situação de subalternização, isto é, de opressão/exploração (CPT 2018:113).

Nos processos de Mata Cavalo e Jacaré dos Pretos, as sentenças foram anuladas em seus efeitos por decisões em segunda instância, cujas fundamentações obedecem à interpretação que mais se aproxima da implementação do artigo 68 do ADCT e do Decreto 4.887/2003 e buscam, na medida do possível, garantir o contraditório e a ampla defesa, embora os processos continuem tramitando, prolongando a insegurança jurídica dos quilombolas sobre a posse e propriedade coletiva de seu território. As ordens de despejos não foram consideradas violações de direitos humanos - provavelmente pela dissociação do território como elemento fundamental para a dignidade das famílias quilombolas -, tampouco a destruição de casas, benfeitorias, pertences e a falta de moradia e termos como racismo institucional e responsabilização sequer apareceram. Há, portanto, uma naturalização da violência contra quilombolas nas ações de reintegração de posse: as decisões são sumariamente cumpridas, com extrema violência e, ainda que posteriormente anuladas, seus efeitos nocivos continuam impactando as vidas dos quilombolas, pois como advertem $\mathrm{A}$. Almeida \& Marín (2012:15): “a estigmatização é um modo eficiente de reproduzir e impor um poder de 
controle e vigilância sobre o grupo marcado, que é despojado de direitos e de reconhecimento como sujeito de direitos".

\section{CONSIDERAÇÕES FINAIS}

Propôs-se, neste artigo, uma reflexão do ponto de vista historiográfico sobre a institucionalização do racismo, com raízes na diáspora africana, escravização e processo de marginalização dos negros no pós-abolição. Nesse sentido, apresentou-se uma revisão bibliográfica, reforçada com dados que retratam os desdobramentos do racismo estrutural no âmbito das instituições do Estado, como a falta de acesso às políticas públicas; também se analisou como o judiciário, que tem sua composição majoritariamente branca, lida com questões relacionadas aos crimes de racismo, bem como em conflitos envolvendo territórios quilombolas.

As definições de racismo ${ }^{1}$ são o retrato de uma sociedade violenta e opressora. Último país a abolir a escravidão, o Brasil está muito distante de reparar as violações de direitos humanos, mesmo com denúncias em órgãos de justiça internacional, já que o sistema de justiça brasileiro não se demonstra eficaz na materialização dos direitos humanos, quando provocado. Ao revés, emprega mais violência quando as tensões pela terra envolvem interesses econômicos. Tendo em vista que, no direito, se permitem diversas interpretações sobre determinados temas, é preciso refletir se a atuação do judiciário nas ações de reintegração de posse se trata de uma dificuldade de se diferenciar a terra, no sentido individual e econômico, com o território coletivo. A reflexão é se esta interpretação é fruto da ignorância da real história do Brasil e da legislação que busca mínima reparação ou se tratam de concessões com finalidades expropriatórias, já que não há, nos dois casos analisados, dúvidas em relação à titularidade das terras, pois reconhecidas pelo próprio executivo.

O que, de fato, nos leva a considerar o Estado como racista é sua atuação paradoxal: de um lado, assume compromisso em titular os territórios quilombolas na Constituição Federal, implementando de forma bastante precária o artigo 68 do ADCT ao longo do tempo, com o reconhecimento dos territórios de Mata Cavalo e de Jacaré dos Pretos, seja pela FCP ou pelo INCRA. De outro, nega este direito, ao ordenar sumariamente que as comunidades sejam despejadas de suas moradias, empregando todo o tipo de violência.

1 Sejam elas de cunho individual, nos casos de cometimento de crime inafiançável, como determina a Constituição Federal de 1988 e lei especial, seja do ponto de vista estrutural, que naturaliza os episódios cotidianos de racismo, ou até mesmo institucional, que se materializa pela ação e/ou omissão de agentes do Estado em políticas públicas diferenciadas, sobretudo aos quilombolas. 
Conclui-se que, neste cenário de conflitos de interesses, o Estado é o maior violador de direitos, ao favorecer fazendeiros, utilizando o despejo como medida primeira, ao arrepio das normas nacionais e internacionais sobre dignidade humana, podendo-se afirmar, nesse aspecto, o nítido racismo institucional.É preciso compreender que o judiciário é instituição constitutiva do Estado e essencial na materialização de direitos que nem sempre são cumpridos pelo executivo, não se admitindo, no caso dos quilombolas, um ativismo judicial às avessas, que nega direitos e emprega violência, potencializando as vulnerabilidades das famílias que há mais de trinta anos buscam a efetivação de seu direito ao território.
O juiz deve buscar a interpretação da norma constitucional sobre o direito ao território quilombola e do decreto que a regulamenta à luz da literatura específica, a fim de compreender o real sentido da política diferenciada às comunidades. Esta interpretação exige conhecimento da própria história do país e de noções de justiça social, imprescindíveis em um Estado pluriétnico e democrático. Nesse sentido, é preciso que se estabeleçam mudanças efetivas no perfil do judiciário, de modo que ele seja mais representativo do ponto de vista pluriétnico, com adoção de políticas diferenciadas para o ingresso e a formação dos profissionais, à luz da dignidade humana.

\section{REFERÊNCIAS}

Almeida, A. W., e R. E. A. Marín. 2012. Os ditos e os “não ditos" da violência e de ações de judicialização contra os quilombolas, in Quilombolas: reivindicações e judicialização dos conflitos. Organizado por A. W. B Almeida, R. E. Acevedo Marín, E. A. Farias Jr., e C. Muller, pp. 11-24. Manaus: Projeto Nova Cartografia Social da Amazônia/UEA Edições.

Almeida, S. L. 2018. O que é racismo estrutural? Belo Horizonte: Letramento.

Araújo, E. F., e G. M. Silva. 2019. Racismo e violência contra quilombos no Brasil. Confluências 21(2):196-208. DOI: https://doi.org/10.22409/conflu.v21i2.34705

Arruti, J. M. 2009. Políticas públicas para quilombos: terra, saúde e educação, in Caminhos convergentes: Estado e sociedade na superação das desigualdades raciais no Brasil. Organizado por M. Paula e R. Heringer, pp. 75-110. Rio de Janeiro: Fundação Heirinch Boll, ActionAid. 
Arruti, J. M., e M. Dowbor. 2015. Desiguais diferentes: diálogos em torno de indígenas, quilombolas e a estrutura de desigualdades no Brasil. Campinas: CEBRAP/CEM/NEPO/CPEI.

Articulação Justiça e Direitos Humanos (JusDh). 2019. Por que os quilombolas não estão, também, do outro lado da mesa dos tribunais? Disponível em: http://www.jusdh.org.br/2019/06/11/porque-os-quilombolas-nao-estao-tambem-do-outro-lado-da-mesa-dos-tribunais/. Acesso em: 6 abr. 2020 .

Associação Brasileira de Antropologia (ABA). 1994. Documentos do Grupo de Trabalho sobre as comunidades negras rurais. Boletim Informativo NUER (1):1-3. Disponível em: https://documentacao. socioambiental.org/documentos/03D00024.pdf. Acesso em: 6 abr. 2020.

Bandeira, M. L. 1990. Terras negras: invisibilidade expropriadora. Terras e territórios de negros no Brasil. Textos e Debates 1(2):7-23.

Barbieri, G. 2019. Família quilombola é despejada de seu território em ação arbitrária da justiça do MT. Terra de Direitos. Disponível em: https://terradedireitos.org.br/noticias/noticias/familia-quilombolae-despejada-de-seu-territorio-em-acao-arbitraria-da-justica-do-mt/23158. Acesso em: 8 abr. 2020.

Beltrão, J. F, e A. C. Oliveira. 2011. Identidade, autonomia e direitos humanos: desafios à diversidade étnica no Brasil. Hendu - Revista Latino-Americana de Direitos Humanos 2(1):56-70. DOI: http://dx.doi. org/10.18542/hendu.v2i1.666

Brasil. 1988. Constituição da República Federativa do Brasil. Diário Oficial da União. Disponível em: http://www.planalto.gov.br/ccivil_03/constituicao/DOUconstituicao88.pdf. Acesso em: 8 abr. 2020.

Brasil. 1989. Lei ${ }^{\circ}$ 7.716, de 5 de janeiro de 1989. Define os crimes resultantes de preconceito de raça ou de cor. Diário Oficial da União. Disponível em: http://www.planalto.gov.br/ccivil_03/leis/17716. htm. Acesso em: 8 abr. 2020. 
Brasil. 2003. Decreto ${ }^{\circ}$ 4.887, de 20 de novembro de 2003. Regulamenta o procedimento para identificação, reconhecimento, delimitação, demarcação e titulação das terras ocupadas por remanescentes das comunidades dos quilombos de que trata o art. 68 do Ato das Disposições Constitucionais Transitórias. Diário Oficial da União. Disponível em: http://www.planalto.gov.br/ccivil_03/decreto/2003/d4887. htm\#: :text=\%C2\%A7\%203o\%20Para\%20a,Art. Acesso em: 8 abr. 2020.

Comissão Interamericana de Direitos Humanos (CIDH). 2006. Relatório n. 66/06. Caso 12. 001. Mérito. Simone André Diniz versus Brasil. Disponível em: http://pfdc.pgr.mpf.mp.br/pfdc/temas-de-atuacao/ Discriminacao/sobras/documentos-tecnicos-de-outros-orgaos/RELATORIO\%20N\%2066-06.pdf. Acesso em: 20 mar. 2020.

Comissão Pastoral da Terra (CPT). 2017. Atlas de conflitos na Amazônia. São Paulo: Editora Entremares. Disponível em: https://www.cptnacional.org.br/component/jdownloads/send/25-cartilhas/14066-atlasde-conflitos-na-amazonia?option=com_jdownloads. Acesso em: 6 abr. 2020.

Comissão Pastoral da Terra (CPT). 2018. Conflitos no campo. Brasil 2018. Disponível em: https://www. cptnacional.org.br/publicacoes-2/destaque/4687-conflitos-no-campo-brasil-2018. Acesso em: 7 abr. 2020.

Comissão Pró-Índio de São Paulo (CPISP). 2020. Observatório Terras Quilombolas. Disponível em: http://cpisp.org.br/direitosquilombolas/observatorio-terras-quilombolas/. Acesso em: 6 abr. 2020.

Conselho Nacional de Justiça (CNJ). 2018. Perfil sociodemográfico dos magistrados brasileiros - 2018. Disponível em: https://static.poder360.com.br/2018/09/49b47a6cf9185359256c22766d5076eb.pdf. Acesso em: 2 nov. 2019.

Coordenação Nacional de Articulação das Comunidades Negras Rurais Quilombolas (CONAQ), e Terra de Direitos. 2018. Racismo e violência contra quilombos no Brasil. Disponível em: https:// terradedireitos.org.br/uploads/arquivos/09-12_Racismo-e-Violencia-Quilombola_CONAQ_Terra-deDireitos_FN_REVISAO_Digital-(1).pdf. Acesso em: 6 abr. 2020. 
Coordenação Nacional de Articulação das Comunidades Negras Rurais Quilombolas (CONAQ). 2019a. Nota de repúdio da CONAQ sobre o arquivamento pelo STF de inquérito contra Bolsonaro por crime de racismo. Disponível em: http://conaq.org.br/noticias/nota-de-repudio-da-conaq-sobre-o-arquivamentopelo-stf-de-inquerito-contra-bolsonaro-por-crime-de-racismo/. Acesso em: 6 abr. 2020.

Coordenação Nacional de Articulação das Comunidades Negras Rurais Quilombolas (CONAQ). 2019b. Carta de repúdio ao despejo de famílias quilombolas de facaré dos Pretos-MT. Disponível em: http:// conaq.org.br/noticias/carta-de-repudio-ao-despejo-de-familias-quilombolas-de-jacare-dos-pretos-mt/. Acesso em: 7 abr. 2020.

Conselho Nacional dos Direitos Humanos (CNDH). 2018. Resolução n. 10, de 17 de outubro de 2018. Dispõe sobre soluções garantidoras de direitos humanos e medidas preventivas em situações de conflitos fundiários coletivos rurais e urbanos. Disponível em: http://www.mdh.gov. br/todas-as-noticias/2018/outubro/resolucao-para-garantia-de-direitos-humanos-em-situacoesde-conflitos-por-terra-e-aprovada-pelo-conselho-nacional-dos-direitos-humanos/copy_of_ Resoluon10Resoluosobreconflitospossessriosruraiseurbanos.pdf. Acesso em: 21 dez. 2018.

Duprat, D. 2018. Conflitos agrários e o judiciário, in Conflitos no campo - Brasil 2017. Coordenado por A. Canuto et al., pp. 119-122. Goiânia: CPT Nacional.

Fernandes, F. 2008. A integração do negro na sociedade de classes. O legado da raça branca. Vol. I. 5 ed. São Paulo: Editora Globo.

Gazeta Digital. 2017. Família quilombola é alvo de despejo e alega estar na área há 200 anos. Disponível em: https://www.gazetadigital.com.br/editorias/cidades/familia-quilombola-e-alvo-de-despejo-e-alegaestar-na-area-ha-200-anos/525268. Acesso em: 6 abr. 2020.

Held, T. M. R. 2017. Quilombo Mata Cavalo: os conflitos agrários e a violação do direito humano ao território étnico em Nossa Senhora do Livramento-MT. ACENO 4(8):68-81. 
Held, T. M. R. 2018. Mata Cavalo: a violação do direito humano ao território quilombola. São Paulo: LiberArs.

Instituto Brasileiro de Geografia e Estatística (IBGE). 2018. Pesquisa Nacional por Amostra de Domicílios Contínua - PNAD Contínua. Disponível em: https://www.ibge.gov.br/estatisticas/multidominio/condicoesde-vida-desigualdade-e-pobreza/17270-pnad-continua.html?=\&t=o-que-e. Acesso em: 6 abr. 2020.

Instituto Nacional de Colonização e Reforma Agrária (INCRA). 2019. Relação de processos de regularização abertos no INCRA. Disponível em: http://www.incra.gov.br/pt/quilombolas.html. Acesso em: 6 abr. 2020.

Leite, I. B. 2018. O projeto político quilombola: desafios, conquistas e impasses atuais. Estudos Feministas 16(3):965-977. DOI: https://doi.org/10.1590/S0104-026X2008000300015

Ministério Público Federal (MPF). 2018. Procuradoria-Geral da República. Notícia de fato N. 1.00.000.006796/2017-13. Noticiado: Jair Messias Bolsonaro. N 542/2018 SFPO/STF. Disponível em: https://www.migalhas.com.br/arquivos/2018/8/art20180828-06.pdf. Acesso em: 8 abr. 2020.

Moreno, G. 1999. O processo histórico de acesso à terra em Mato Grosso. Geosul 14(27):67-90.

Moura, C. 1994. Dialética radical do Brasil Negro. São Paulo: Editora Anita.

Munanga, K. 2001. Origem e história dos quilombos em África, in Os quilombos na dinâmica social do Brasil. Organizado por C. Moura, pp. 21-35. Maceió: Ed. ADUFAL.

Nascimento, A. 2019. O Quilombismo: documentos de uma militância Pan-Africanista. 3 ed., rev. São Paulo: Editora Perspectiva; Rio de Janeiro: Ipeafro.

Plataforma Brasileira de Direitos Humanos, Econômicos, Sociais e Culturais (DHESCA Brasil). 2005. Relatório da Missão ao Estado de Mato Grosso [Realizada entre 15 e 24 de agosto de 2004]. Rio de Janeiro: Plataforma DHESC. Disponível em: http:// www.dhnet.org.br/dados/relatorios/r_dhescas_br/missao_2004_mt_dhesc_meio_ambiente.pdf. Acesso em: 6 abr. 2020. 
Programa de Combate ao Racismo Institucional (PCRI). 2006. Articulação para o Combate ao Racismo Institucional. Identificação e abordagem do racismo institucional. Brasília: PCRI.

Santos, G. A. 2015. Nem crime, nem castigo: o racismo na percepção do judiciário e das vítimas de atos de discriminação. Revista do Instituto de Estudos Brasileiros (62):184-207. DOI: https://doi.org/10.11606/ issn.2316-901X.v0i62p184-207

Schramm, F. P. 2019. No atual ritmo, Brasil levará mil anos para titular todas as comunidades quilombolas. Terra de Direitos. Disponível em: https://terradedireitos.org.br/noticias/noticias/no-atual-ritmo-brasillevara-mil-anos-para-titular-todas-as-comunidades-quilombolas/23023. Acesso em: 1 nov. 2019.

Supremo Tribunal Federal (STF). 2018. Inquérito 4.694 Distrito Federal. Autor: Ministério Público Federal. Investigado: Jair Messias Bolsonaro. Inteiro Teor do Acórdão. Primeira Turma. Rel. Min. Marco Aurélio. 1-70. Disponível em: http://portal.stf.jus.br/processos/downloadPeca.asp?id=15340588165\&ext=. pdf. Acesso em: 13 set. 2020.

Treccani, G. D. 2006. Terras de quilombo: caminhos e entraves do processo de titulação. Belém: Secretaria Executiva de Justiça/Programa Raízes.

Tribunal Regional Federal da Primeira Região (TRF1). 2017. Agravo de Instrumento N. 100131637.2017.4.01.3600/MT. Agravante: Fundação Cultural Palmares. Agravado: Espolio de Elzio Saldanha. Relatora: Juíza Federal Rogéria Maria Castro Debelli. Disponível em: https://processual.trf1.jus.br/ consultaProcessual/numeroProcesso.php?secao=TRF1. Acesso em 13 set. 2020.

Tribunal Regional Federal da Primeira Região (TRF1). 2020. Apelação Cível N. 000930519.2014.4.01.3600/MT. Apelante: Fundação Cultural Palmares. Apelado: Maria Terezinha Leite Nadaf. Relator: Pires Brandão. Disponível em: https://www.jusbrasil.com.br/processos/172888212/processon-0009305-1920144013600-do-trf-1?topic-monitoring-flow =0009305-19.2014.4.01.3600\&ref=amp. Acesso em 13 set. 2020. 
Venturini, A. C., e J. Feres Júnior, 2020. A desigualdade racial no judiciário brasileiro. Grupo de Estudos Multidisciplinares da Ação Afirmativa. Disponível em: http://gemaa.iesp.uerj.br/infografico/a-desigualdade-racial-no-judiciario-brasileiro/. Acesso em: 20 mar. 2020. 